\title{
Do sonho da ascensão social à vida de operário: os caixeiros do Rio de Janeiro da virada do século XIX-XX
}

\author{
From the dream of social ascent to the life of a laborer: shop clerks in \\ Rio de Janeiro at the turn of the nineteenth to twentieth centuries
}

\author{
Gisele Sanglard \\ Pesquisadora visitante do Departamento de Patrimônio Histórico/Casa de Oswaldo Cruz/Fiocruz. \\ sanglard@coc.fiocruz.br
}

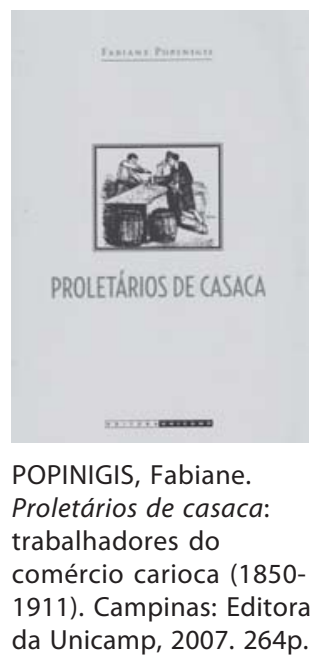

\begin{abstract}
$\mathrm{O}$ livro de Fabiane Popinigis, Proletários de casaca, fruto de sua tese de doutorado defendida no Programa de Pós-graduação em História da Universidade de Campinas (Unicamp), nos convida a entrar no mundo dos caixeiros da cidade do Rio de Janeiro, da virada do século XIX para o XX. O cenário que se descortina diante do leitor, para além das questões 'classistas' ou ligadas ao mundo do trabalho, aponta para as relações sociais entre caixeiros e proprietários, a questão da moradia, dos preconceitos étnicos intra e extragrupo e a solidariedade grupal, entre outros temas ligados às relações de trabalho e sociabilidade, às condições de moradia e ao lazer - como a autora define.
\end{abstract}

Ao ler esse livro, é impossível não pensar em aoutra obra que também mergulhou no mundo dos empregados do comércio carioca (estivadores, padeiros etc.) do mesmo período. Trata-se de Trabalho, lar e botequim: o quotidiano dos trabalhadores cariocas na Belle Époque, de Sidney Chalhoub, orientador de Fabiane. Ambos têm nos processos judiciais dos crimes cometidos por esses trabalhadores sua principal fonte de pesquisa. O tempo que separa essas publicações marca e aprofunda as diferenças entre elas.

O objetivo do livro de Fabiane é o estudo da identidade da classe de trabalhadores no comércio, adotando como balizadores cronológicos 1850, quando surgem as primeiras associações beneficentes ligadas a essa categoria - o que é percebido pela autora como a primeira organização 'política' da classe -, e 1911, momento da agitação política do grupo. Para o desenvolvimento do argumento, Fabiane divide o livro em três capítulos: o primeiro destinado à discussão bibliográfica sobre o tema, no qual a autora trata da identidade do empregado em contraposição à do 'operário', tem como interlocutores principais a historiografia anglo-saxônica sobre as classes operárias e os processos cíveis e ações comerciais vinculadas ao grupo.

No segundo capítulo, a autora se dedica a analisar o que considerou "atuação política e institucional dos caixeiros" (p.30), desde a criação das primeiras associações beneficentes até a promulgação de leis de proteção ao trabalhador. Esse capítulo tem como referência teórica, no que tange aos movimentos sociais, a historiografia francesa. 
Por fim, no último capítulo, Popinigis mergulha no universo dos processos criminais envolvendo os empregados no comércio e a relação, cada vez mais tensa, entre patrões e empregados. São as transformações sociais que começam a ocorrer no mundo do trabalho. A autora analisa quem eram esses caixeiros e como a percepção que eles tinham de si e do outro, o patrão, vai-se alterando ao longo do século XIX até alcançar seu ponto crítico nas primeiras décadas do século XX. Cabe salientar os seguintes pontos discutidos pela autora: a imagem que aqueles homens constroem sobre si e suas profissões; a imagem que os outros têm deles; e o processo de proletarização que a classe vive no início do século XX e que alterará sobremaneira essa percepção.

Popinigis destaca o fato de os caixeiros serem percebidos, principalmente na literatura, como arrivistas ou como avaros. São esses os dois modelos pelos quais poderíamos imaginar o caixeiro típico, aquele que foi descrito por Martins Pena, Joaquim Manoel de Macedo, Fernando Pessoa e Aluízio de Azevedo - conforme ressaltado pela autora. Principalmente na obra deste último, a imagem dos caixeiros é negativa. Em todo caso, a história dessa classe de trabalhadores é igual à de todos aqueles que, ainda crianças, chegavam ao Brasil vindos de Portugal:

\begin{abstract}
Na hora de embarcar ouviam isto: 'Para com teu patrão, meu rico filho, muita submissão e respeito, que outro não será o que há de te dar, na falta de teu pai, a mesa, o ensino e o futuro' ... Quando o pobre imigrante ingressa na sórdida vendoca, onde há de perder cedo ou tarde, ... a inocência e o caráter ... o prato que ele encontra, se não é ótimo, é pelo menos, cheio e farto ... Com a idade vai aprendendo a conhecer o mundo pela filosofia do patrão. ... Com esse patrão instrui-se, aprende a burlar e a mentir... (Edmundo, 1957, p.357-362).
\end{abstract}

Luiz Edmundo (1957) traça a imagem do caixeiro como a do imigrante, cheio de ilusões, que trabalha muito, aprende na prática a arte da venda, aos trinta anos se torna interesseiro - termo usado para designar aquele que tem interesse no negócio - e aos 35 anos abre seu próprio comércio, com as economias amealhadas. O caixeiro de Luiz Edmundo vive na venda, em caixote de madeira, tem relações com o cortiço - aliás, manter um cortiço é a ampliação dos negócios desses agora comerciantes. Nessa perspectiva, ser proprietário de comércio e de cortiço seria o grande anseio desses caixeiros.

Esse é o ponto crucial do livro: as dificuldades cada vez maiores de ascensão social, de um lado, e a proletarização da categoria, de outro, darão a tônica das relações entre patrão e empregado. É justamente essa dialética o que se ressalta no título da obra: a ideia da ascensão social que a casaca traduz e a proletarização da classe. A ascensão social, para os caixeiros, era sinônimo de tornar-se proprietário do negócio. Foi esse o destino do barão de Mauá, de Cândido Gaffrée e Eduardo Palassin Guinle. Começaram os três como caixeiros, guarda-livros, e se tornaram sócios solidários nos seus negócios até estarem suficientemente capitalizados para voar sozinhos e se tornar homens riquíssimos: o primeiro no Império e os demais, na virada do século (Sanglard, 2008). Tornar-se um bem-sucedido proprietário de negócio, talvez, fosse o télos para muitos deles.

Todavia, a autora não está preocupada com os tipos 'exemplares', e sim com o médio e, sobretudo, com aquele que cometeu algum delito e, por isso, passou a frequentar as páginas dos jornais e figurar nos processos criminais. 
O caixeiro típico se considerava diferente dos operários por vários motivos: a começar pelas vestimentas, pelo fato de muitos serem letrados ${ }^{1}$ e de as relações entre patrões e empregados serem pautadas no paternalismo, o que permitia que algumas de suas reivindicações fossem atendidas. Luiz Edmundo (1957) deixa bem claro como era a possibilidade de ascensão: o patrão 'ensinava' ao aprendiz, que se iria tornar, um dia, também, patrão.

Contudo, a virada do século XIX para o XX viu surgirem, tanto na Europa quanto no Brasil, diversos partidos voltados para a causa operária, que defendiam ou não a greve como principal forma de reivindicação. No Brasil, a Primeira República teve como uma de suas marcas o início do movimento operário, imbuído de ideais positivistas, anarquistas ou socialistas.

Nesse período de efervescência ideológica, os caixeiros estruturam-se como movimento organizado, em torno de sindicatos e periódicos. Aos poucos vão-se configurando como classe - fruto de um longo processo, cujos resultados podem ser mensurados nas ações e instituições coletivas (Batalha, 2006, p.163), tal qual a Associação dos Empregados no Comércio (AEC) e as inúmeras associações beneficentes (classistas) então existentes. Entretanto, o interior dessa 'classe' era dividido. A AEC não era considerada representativa de todos os caixeiros, devido ao implicado alto custo e a sua postura, que comungava mais com os interesses patronais do que com os dos empregados - não foi à toa que a instituição teve como beneméritos grandes industriais como os Guinle. Ainda assim, é certo que essa associação, criada em 1860, esteve por muito tempo voltada para as antigas formas de negociação, nas quais o paternalismo reinava.

Se os caixeiros se percebiam diferentes dos operários, se a percepção de classe já estava configurada desde o século XIX, por que eles perdem a capacidade de negociação no início do século XX?

A autora direciona a resposta para as transformações sociais pelas quais passa o país no período. No século XIX, as associações caixeirais eram consideradas de solidariedade horizontal e voltadas para eles próprios e suas famílias, o que as inseria na lógica da assistência típica da colonização portuguesa, voltada para corporações de ofício e irmandades laicas, mas de devoção. Na República, houve a expectativa de uma maior intervenção do Estado nas relações entre trabalhadores e patrões - o que gerava desconfiança por parte destes últimos, que não viam com bons olhos a interferência do Estado em seus negócios privados. $^{2}$ No entender da autora, a proximidade entre patrão e empregado dificultava a solidariedade horizontal comum durante o liberalismo.

A grande inspiração dos caixeiros, em suas reivindicações, era a situação de seus pares franceses, que, nesse período, lutavam por uma redução na jornada de trabalho e por folga semanal aos domingos - uma das mais antigas reivindicações da classe. Acompanhar a transformação do discurso político da classe em prol do descanso semanal ou do 'fechamento das portas', como era dito na época, por si só possibilitaria um belo trabalho. Durante o Império, com a forte influência religiosa, o discurso pautava-se na observância dos dias sagrados e dos preceitos religiosos; com o advento da República e a separação entre Estado e Igreja, o discurso passou a ter foco na cidadania. Para os patrões, em sua lógica paternalista, tratava-se de atender a algumas das reivindicações dos empregados. 
Outro ponto examinado pela autora acerca dessa reivindicação é a apropriação dos códigos vigentes: o lazer como contraponto à criminalidade, defendido pelos caixeiros; ou o discurso higienista, próprio desse período, adaptado por certos proprietários para evitar fechar seus estabelecimentos. Como patrões e empregados habitavam parte do estabelecimento comercial, o 'fechamento das portas' impediria a aeração, ventilação e insolação de suas moradias, impossibilitando a manutenção dos três pilares do higienismo. Para esses patrões somente as 'portas abertas' permitiriam a boa circulação de ar, vento e entrada de sol em suas residências. E 'portas abertas' significava caixeiros trabalhando.

Se o movimento dos comerciários franceses inspirava os cariocas, que ajustavam as reivindicações às necessidades locais, o mesmo não se pode dizer dos patrões.

Na França, o período estudado pela autora foi significativo para as relações entre patrões e empregados. Popinigis chama atenção para a contemporaneidade das reclamações dos comerciários franceses e brasileiros a favor da diminuição da jornada de trabalho e das folgas semanais. Janet Horne (2004) ressalta que a década de 1880 foi muito propícia para o surgimento de um novo contrato social, capitaneado por republicanos liberais que buscavam soluções duráveis para o problema social francês. Esses homens eram industriais respeitáveis e também deputados na Assembleia Nacional.

O pano de fundo desse movimento foram os inúmeros afrontamentos políticos que varreram a França no século XIX; os movimentos sociais, incluindo as reivindicações dos comerciários franceses ressaltadas por Popinigis no segundo capítulo; o impacto das ciências sociais nascentes; e a crise do liberalismo, que anunciava um longo debate sobre a legitimidade do papel do Estado na sociedade industrial. Como resultado destacam-se a invenção da agenda social, a mudança de foco do pobre para o operário pobre e a conquista de uma legislação protetora.

Do lado patronal, houve inúmeras iniciativas de incentivo à formação de círculos operários, considerados espaços cívicos. Esses círculos podiam ser percebidos como um neopaternalismo, manifestação de um posto em que os patrões mantinham espaços de recreação, lazer e de cursos para seus empregados e familiares. Por outro lado, significavam uma auto-nomia do movimento operário, pois asseguravam a estabilidade da força de trabalho por meio da educação cívica e da comunicação entre as classes, e ainda integravam a reforma social conseguida por meio da associação voluntária e da integração entre os trabalhadores. Outra questão surgida nesse período foi o patrocínio às sociedades de auxílio mútuo, entendidas como necessidades do mundo do trabalho. ${ }^{3} \mathrm{O}$ mutualismo ${ }^{4}$ passou a ser encarado como complementar para a organização dos operários franceses.

No Brasil, o movimento operário também contabilizou suas vitórias, mas, como os caixeiros não eram operários, não tiveram as vantagens dos 'proletários'. Por configurar uma categoria da elite trabalhadora, os caixeiros viram-se em um dilema cada vez maior: manter a singularidade da classe e se 'proletarizar' aos poucos, ou assumir-se como operários e obter os direitos conquistados por estes últimos. Os caixeiros acabavam por ficar no meio do caminho, comemorando vitórias parciais que logo eram derrubadas pelas ações patronais.

O certo é que as velhas práticas paternalistas ainda vigoravam entre caixeiros e patrões. Os patrões ainda esperavam lealdade - a 'submissão' e o 'respeito' a que Luiz Edmundo se referia na sua crônica - de seus empregados, e os caixeiros a usavam para obter algumas 
vantagens. Conforme destaca Chalhoub (2001), essas práticas não coadunavam mais com o ritmo frenético do comércio e da indústria cariocas do início do século XX. De acordo com Luiz Edmundo (1957), a manutenção das velhas práticas se perpetuava no jovem imigrante, caixeiro, que se tornou 'interesseiro' e, por fim, proprietário que "pensando no que foi, manda buscar à terra novos escravos brancos, alminhas puras como a dele o foi, para explorar e corromper" (p.363).

$\mathrm{O}$ trabalho de Fabiane Popinigis apresenta-nos um retrato da classe dos caixeiros na virada do século XIX para o XX e suas estratégias para conseguir melhores condições de trabalho e manter as vantagens que singularizaram a classe - mesmo que elas estivessem cada vez mais distantes. Esse período de transição é rico para percebermos o horizonte de expectativas que eles construíram para si. Foi um tempo de mudanças sociais fortes, quando o caixeiro - preso na dialética entre um 'espaço de experiência' e um 'horizonte de expectativas' cada vez mais distante, e entre a ideia que tinha de si e aquilo que estava conseguindo obter - equilibrava-se entre a submissão e a revolta e forjava, assim, sua nova identidade: a do 'proletário de casaca' - com condições de vida e trabalho deterioradas, sem o glamour de outrora.

\section{NOTAS}

${ }^{1}$ Ser 'letrado' era exigência para aqueles que aspiravam a tornar-se guarda-livros e, por conseguinte, alcançar a ascensão social.

${ }^{2}$ A intervenção era possível, desde que consentida entre as partes, como no caso dos preços do café.

${ }^{3}$ Os auxílios eram referentes a doença, machucado, acidente, velhice, maternidade ou morte.

${ }^{4}$ O mutualismo no Brasil teve no jurista Ataulfo de Paiva (1867-1955) seu grande divulgador e defensor. Em sua opinião o mutualismo preencheu uma "lacuna moral e econômica", surgida no meio de crises permanentes e fundamentais dos corpos dirigentes da sociedade. Com espírito social, tinha por objetivo suavizar a indigência. Segundo Paiva (1916, p.93), "distintas em sua origem, [assistência e previdência] devem viver unidas, complementando-se mutuamente. A assistência implica a ideia de liberalidade, resulta da concessão de um favor, referindo-se ao indigente. O seguro procede do exercício de um direito, presume o cumprimento de uma obrigação, dirigindo-se ao previdente. O predomínio de uma das forças constituía perigosa tentativa. Um laço harmônico deve sustentar e prender os dois poderosos elementos. Tão íntimas e tão necessárias são as relações entre ambos, que uma influência recíproca se impõe em benefício do interesse comum" (grifos do original).

\section{REFERÊNCIAS}

BATALHA, Cláudio.

Formação da classe operária e projetos de identidade coletiva. In: Ferreira, Jorge; Delgado, Lucilia de Almeida Neves (Org.). O Brasil Republicano: o tempo do liberalismo excludente - da proclamação da República à Revolução de 1930. Rio de Janeiro: Civilização Brasileira. p.161-189. 2006.

CHALHOUB, Sidney.

Trabalho, lar e botequim: o quotidiano dos trabalhadores cariocas na Belle Époque. Campinas: Editora da Unicamp. 2001.

EDMUNDO, Luiz.

O Rio de Janeiro de meu tempo. Rio de Janeiro:

Conquista. v.2. 1957.
HORNE, Janet.

Le musée social: aux origines de l'État providence. Paris: Belin. 2004.

PAIVA, Ataulfo de.

Justiça e assistência: os novos horizontes. Rio de Janeiro: Typographia do Jornal do Commercio. 1916.

SANGLARD, Gisele.

Entre os salóes e o laboratório: Guilherme Guinle, a saúde e a ciência no Rio de Janeiro, 19201940. Rio de Janeiro: Editora Fiocruz. 2008. 